\title{
Systematic literature review and meta- analysis on the epidemiology of methylmalonic acidemia (MMA) with a focus on MMA caused by methylmalonyl- CoA mutase (mut) deficiency
}

\author{
Tímea Almási ${ }^{1 *}$ (D, Lin T. Guey² ${ }^{2}$ Christine Lukacs², Kata Csetneki ${ }^{1}$, Zoltán Vokó ${ }^{1,3}$ and Tamás Zelei ${ }^{1}$
}

\begin{abstract}
Methylmalonic acidemia/aciduria (MMA) is a genetically heterogeneous group of inherited metabolic disorders biochemically characterized by the accumulation of methylmalonic acid. Isolated MMA is primarily caused by the deficiency of methylmalonyl-CoA mutase (MMA mut; EC 5.4.99.2). A systematic literature review and a meta-analysis were undertaken to assess and compile published epidemiological data on MMA with a focus on the MMA mut subtype (OMIM \#251000). Of the 1114 identified records, 227 papers were assessed for eligibility in full text, 48 articles reported on disease epidemiology, and 39 articles were included into the quantitative synthesis. Implementation of newborn screening in various countries has allowed for the estimation of birth prevalence of MMA and its isolated form. Meta-analysis pooled point estimates of MMA (all types) detection rates were 0.79, 1.12, 1.22 and 6.04 per 100,000 newborns in Asia-Pacific, Europe, North America and the Middle East and North Africa (MENA) regions, respectively. The detection rate of isolated MMA was $<1$ per 100,000 newborns in all regions with the exception of MENA where it approached 6 per 100,000 newborns. Few studies published data on the epidemiology of MMA mut, therefore no meta-analysis could have been performed on this subtype. Most of the identified papers reported birth prevalence estimates below 1 per 100,000 newborns for MMA mut. The systematic literature review clearly demonstrates that MMA and its subtypes are ultra-rare disorders.
\end{abstract}

Keywords: Inherited metabolic disorder, Methylmalonic acidemia/aciduria, Methylmalonyl-CoA mutase deficiency, Epidemiology, Meta-analysis, Newborn screening

\section{Background}

Methylmalonic acidemia or aciduria (MMA) is a genetically heterogeneous group of disorders originating from impaired metabolism of certain amino acids (isoleucine, methionine, threonine, or valine), odd-chain fatty acids or cholesterol esters. MMA is biochemically characterized by the accumulation of methylmalonic acid in all body fluids and tissues [1]. Two main forms can be distinguished: isolated MMA and combined MMA. The isolated form may be caused by a complete or partial deficiency of the enzyme methylmalonyl-coenzyme A

\footnotetext{
* Correspondence: timea.almasi@syreon.eu

'Syreon Research Institute, Mexikói str. 65/A, Budapest H-1142, Hungary

Full list of author information is available at the end of the article
}

(CoA) mutase (mut; mut ${ }^{0}$ enzymatic subtype or mut ${ }^{-}$ enzymatic subtype, respectively) (EC 5.4.99.2) (Online Mendelian Inheritance in Man (OMIM) number "609058), a defect in the transport or synthesis of its cofactor, adenosyl-cobalamin (cblA, cblB, cblD-MMA, $\mathrm{cblH})$, or by a deficiency of the enzyme methylmalonylCoA epimerase [2]. Combined MMA presents with homocystinuria/ homocystinemia (cblC, cblD-MMA/ $\mathrm{HC}, \mathrm{cblF}, \mathrm{cblJ}$ ) and also with malonic acidemia/aciduria (CMAMMA type) [3]. The majority of MMA patients present with clinical signs and symptoms within the first few days or weeks of life $[4,5]$ and the overall prognosis is generally poor, with the occurrence of intermittent life-threatening acute metabolic decompensations 
precipitated by catabolic factors and significant longterm sequelae including neurologic and renal impairment $[6,7]$.

The inclusion of MMA in newborn screening panels has allowed for early diagnosis. The impact of newborn screening on the long-term outcomes of MMA remains to be fully elucidated [7], however according to the European registry and network for Intoxication type Metabolic Disorders (E-IMD), newborn screening is effective in reducing the time to diagnosis for late-onset patients and reduces the likelihood of movement disorders in MMA patients who are responsive to cobalamin supplementation [8].

Although newborn screening studies have been published in different regions, a systematic review of the epidemiology literature in MMA has not been performed to date. Thus, a systematic literature review (SLR) followed by a meta-analysis was undertaken to compile and assess published epidemiological data on methylmalonic acidemia (MMA) with a focus on the isolated form caused by methylmalonyl-CoA mutase deficiency (MMA mut).

\section{Methods}

\section{Systematic literature review}

The literature search was performed covering Medline, Embase, Cochrane Database of Systematic Reviews, Centre for Reviews and Dissemination (CRD) Database, Academic Search Complete, Cumulative Index to Nursing and Allied Health Literature (CINAHL) and PROSPERO databases. Websites of rare disease organizations were also searched for eligible studies. The search strategies used in scientific databases with the date of the search and number of hits are summarized in Table S1 [see Additional file 1]. The exclusion criteria of the title/abstract screening and full-text reviews are summarized in Fig. 1 and are detailed in Table S2 [see Additional file 1]. A snowball method was also used to identify further relevant studies among the references of full text papers.

Data extraction was performed by two independent researchers, and conflicts were resolved by discussion until a consensus was reached. Published data were considered relevant for the disease epidemiology if the reference population - from which the cases were identified - was representative of the general population of the investigated country or region. Reports on national screening programs with $\sim 100 \%$ population coverage and analyses of national statistics were considered to provide the most accurate data on disease epidemiology. Reports on screening programs not covering $\sim 100 \%$ of the population were considered to be eligible if a relatively large, random sample was used or the screening program had a multicenter design. Studies reporting on selected patient populations (e.g. patients with clinical suspicion of inborn error of metabolism) were excluded. Risk of bias was evaluated on study-level, using the tool developed by Hoy et al. [9] designed to assess methodology and risk of bias in prevalence studies [9]. The checklist consists of 10 close-ended questions assessing the overall risk of study bias both on the level of internal and external validity. Risk of bias was assessed for all studies. A summary score of $0-3$ was indicated as low risk, $4-6$ as moderate risk and $7-10$ as high risk.

\section{Meta-analysis}

Studies with moderate or low risk of bias as determined by the Hoy tool were eligible for the quantitative synthesis [9]. Overlap among the study populations across multiple studies were rigorously investigated by reviewing countries/regions, study periods, data sources and study cohorts. Overlapping populations were excluded and the publication with the more complete dataset was included in the meta-analysis.

Random effects meta-analysis was performed including all identified studies presenting disease occurrence data, regardless of the calculation method used (i.e. birth prevalence, lifetime risk and cumulative incidence). Heterogeneity between the individual study estimates was determined by the chi-square test and the I-square $\left(\mathrm{I}^{2}\right)$ statistics. The Metaprop module for STATA was used to perform all meta-analyses in STATA SE 15.0. This routine provides procedures for pooling proportions in a meta-analysis of multiple studies. The confidence intervals of the individual study estimates are based on the exact binomial (Clopper-Pearson) procedure [10]. Confidence intervals for the pooled estimate were calculated after Freeman-Tukey double arcsine transformation.

The meta-analysis was carried out for the following regions: North America, Europe, Asia-Pacific, Middle East and North Africa. Time trends were analyzed by performing a subgroup analysis covering three different time periods: -1980, 1981-2000, 2001-present. In order to decrease the heterogeneity of epidemiological measures, a sensitivity analysis was undertaken by excluding studies not presenting birth prevalence data.

\section{Results}

A total of 1114 records were identified by the literature searches. After duplicates were removed, 892 records were screened by their titles and abstracts from which 160 articles qualified for a full-text review. The snowball method identified 67 extra articles which were mainly newborn screening reports that did not mention MMA-related terms in their title, abstract or keywords, and therefore were not identified by the search strategy. In total, 227 articles were assessed for eligibility in full text and 48 were considered eligible for the qualitative 


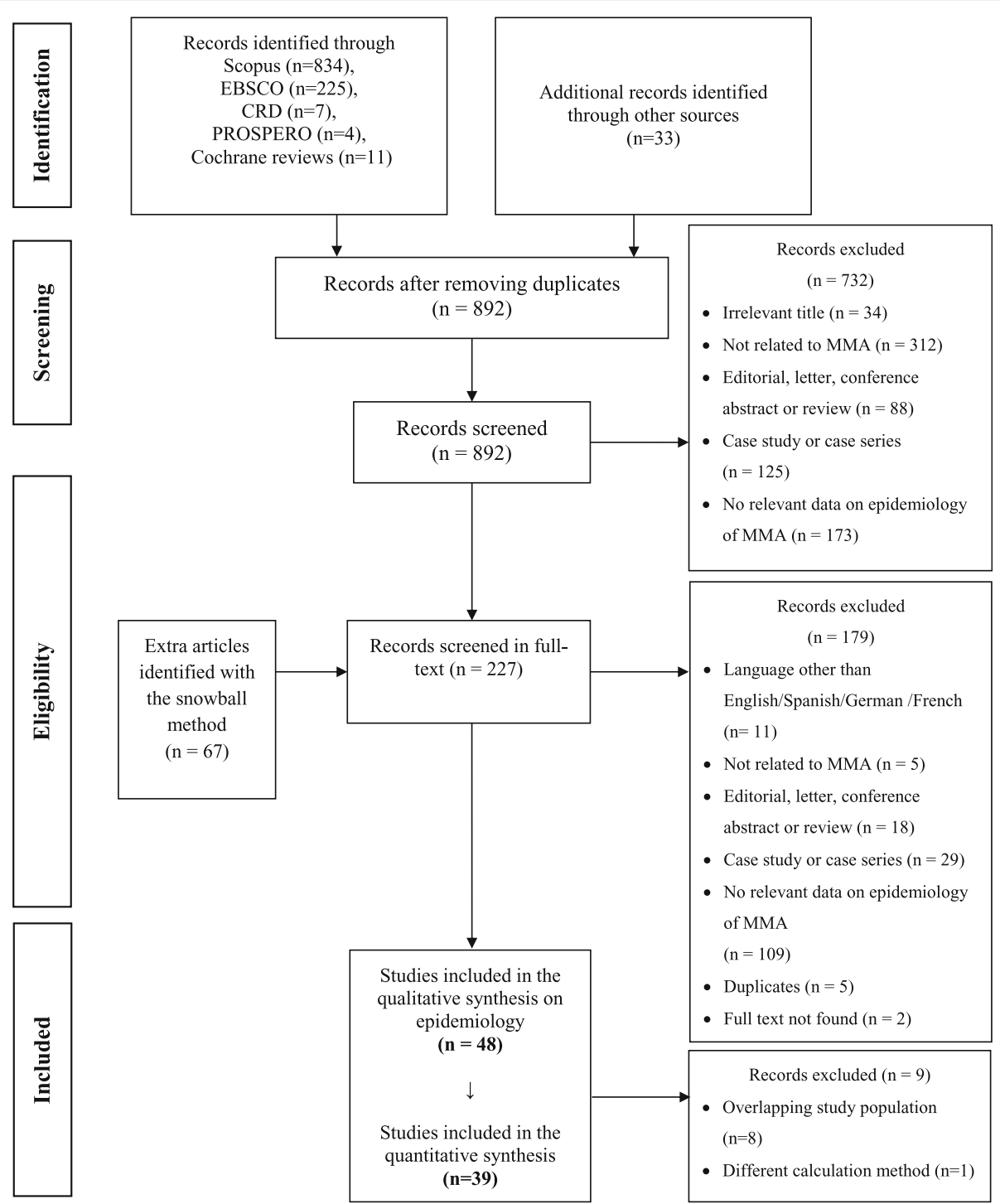

Fig. 1 Flow of information diagram

synthesis (Fig. 1). Among the 48 articles there were 8 overlapping studies [11-18] and one article used a different calculation method than the remaining articles [19]; these were excluded from the quantitative analysis.

The literature review provided data from 25 countries from 4 different geographic regions. The majority of the publications originated in developed countries.

A variety of epidemiological terms were used across the studies to report the proportion of newborns who were or would be affected by MMA. Due to this heterogeneity the reported measures were categorized based on their calculation methods into scientifically acceptable epidemiological terms (Table S3) [see Additional file 1]. The vast majority of articles reported on newborn screening programs, providing estimates on birth prevalence, defined as the number of affected newborns divided by the total screened population. Three articles followed a specific birth cohort over time and counted the number of diagnoses over the follow-up period, providing estimates on the cumulative incidence in the birth cohort $[11,20,21]$. In six cases, authors estimated the lifetime risk at birth - a special case of cumulative incidence in which the period of time studied is the entire remaining lifetime - by dividing the newly diagnosed cases in an observational period by the number of all live births during the same time period [22-28]. Although the calculation methods differ, the difference in the results is small if it is assumed that MMA appears early in life, the disease occurrence is more or less constant, the size of birth cohorts and the diagnostic methods did not change significantly over time and all patients who have the underlying mutation will present with clinical 
symptoms over their lifetime. Based on these assumptions, we use the term "detection rate" for the three above-mentioned measures throughout the paper. One study reported the proportion of affected patients divided by the total population at a certain date providing point prevalence data for the disease [19]. Point-prevalence is not comparable to the three above-mentioned calculation methods, therefore it was omitted from the quantitative synthesis.

\section{Epidemiology data on MMA (all types)}

The pooled point estimates of the detection rates were 0.79 (CI: 0.44-1.21), 1.12 (CI: 0.50-1.91), 1.22 (CI: 0.612.01) and 6.04 (CI: 4.02-8.41) per 100,000 newborns in Asia-Pacific, Europe, North America and MENA, respectively. Regional and country-specific detection rates are provided in Fig. $2[11-18,20,21,23-59]$ and Fig. 3 [11, 16-18, 23, 25-30, 32, 39-45, 47, 50-54, 60, 61]. Results of the meta-analyses along with the conducted sensitivity analyses can be found in Table 1 .

In North America the detection rate of MMA was the lowest in Massachusetts $(<0.45 / 100,000)$ and the highest in Ontario $(3.60 / 100,000)[29,30]$. A minor increasing tendency was observed when analyzing different time periods in North America; the pooled point estimate was 0.96 (CI: $0.28-1.97)$ in the period of "-1980" while it was 1.53 (CI: $0.67-2.68)$ per 100,000 newborns in the period of "2001-present".

Publications from Europe show a heterogeneous picture with two publications reporting relatively high figures from the Southern region. Juan-Fita et al. (2012) identified 10 MMA cases in Murcia, Spain during a pilot screening program covering 71,595 newborns that resulted in a detection rate of 13.97 per 100,000 newborns [31]. Authors explained this high number by the relatively high rate of immigration from North Africa and South America. Scolamiero et al. (2015) reported on a pilot screening program from Campania, Italy, in which 45,466 newborns were screened. They reported 3 identified MMA cases that resulted in a detection rate of 6.60 per 100,000 newborns [32]. European data were not available before 1980 and only a minor increase was observed between the period of "1981-2000" and "2001-present" (1.18 (CI: 0.95-1.43) vs. 1.55 (CI: 0.513.02) per 100,000 newborns).

In the Asia-Pacific region the detection rate of MMA was the lowest in New Zealand $(<0.54 / 100,000)$ and the highest in Malaysia $(6.61 / 100,000)[27,33]$. The latter estimate was based on a pilot screening program including 11 public hospitals across the country which screened 30,247 newborns; thus the representativeness of this study is uncertain. No time trend was observed.

In the MENA region, a tendency towards increased detection rates was observed, with estimations ranging from 1.77 in the United Arab Emirates to $6.45-14.48$ in Saudi Arabia per 100,000 newborns [11, 25, 34-38]. Time trends showed decreasing tendencies over the years; while the pooled point estimate was 8.66 per 100,000 newborns (CI: 4.79-13.54) in the period of 1981-2000, it decreased to 5.21 (CI: 3.67-6.97) per 100,000 newborns in the period of "2001-present". However, these subgroup analyses included only a few (2 and 4 respective) studies. The only paper reporting point prevalence data was from Oman, where authors reported on 8 MMA patients, resulting in a point prevalence of 0.29 per 100,000 inhabitants [19].

\section{Epidemiology data published on isolated MMA}

The pooled point estimates were 0.38 (CI: 0.09-0.79), 0.51 (CI: $0.32-0.74), 0.60$ (CI: $0.16-1.23$ ) and 5.69 (CI: 2.54-9.87) per 100,000 newborns in North America, Asia-Pacific, Europe and MENA, respectively.

In North America the lowest detection rate was published from Massachusetts by Levy et al. [29], where no cases were identified out of 222,302 infants [29]. The highest estimate was 1.59/100,000 newborns in New York State where 16 isolated MMA cases were detected among the 1,006,325 screened newborns [39]. No clear tendency was indicated by the time-specific subgroup analysis.

In Europe the highest estimate originated from Campania, Italy (4.40/100,000 newborns) and the lowest value was reported from Athens, Greece where no MMA cases were identified among the 45,000 screened newborns $[32,40]$. As all identified articles reporting on the epidemiology of isolated MMA were published after 2001, no time-specific subgroup analysis was conducted.

In Asia-Pacific, the lowest estimate was $<0.28 / 100,000$ newborns in New-Zealand [27], while the highest estimate was identified in South Korea $(2.15 / 100,000$ newborns) [41]. Time-specific subgroup analysis showed a marginal decrease between the period of "1981-2001" and "2001-present".

In the MENA region, the detection rates were higher, ranging from 3.97 to 6.65 per 100,000 newborns [11, 25, 37]. No time-specific subgroup analysis could be conducted as both studies included into the meta-analysis were published after 2007.

\section{Epidemiology data published on MMA caused by mutase deficiency (MMA mut)}

The literature reporting on the epidemiology of MMA caused by mutase deficiency was scarce and the data was heterogeneous. Therefore, no quantitative meta-analysis could be performed in the case of this subtype.

In the United States, Therrell et al. [60] reported aggregate statistics of newborn screening programs which covered 25,219,021 newborns in the period of 20012010 [60]. The authors detected 158 MMA mut cases, a 


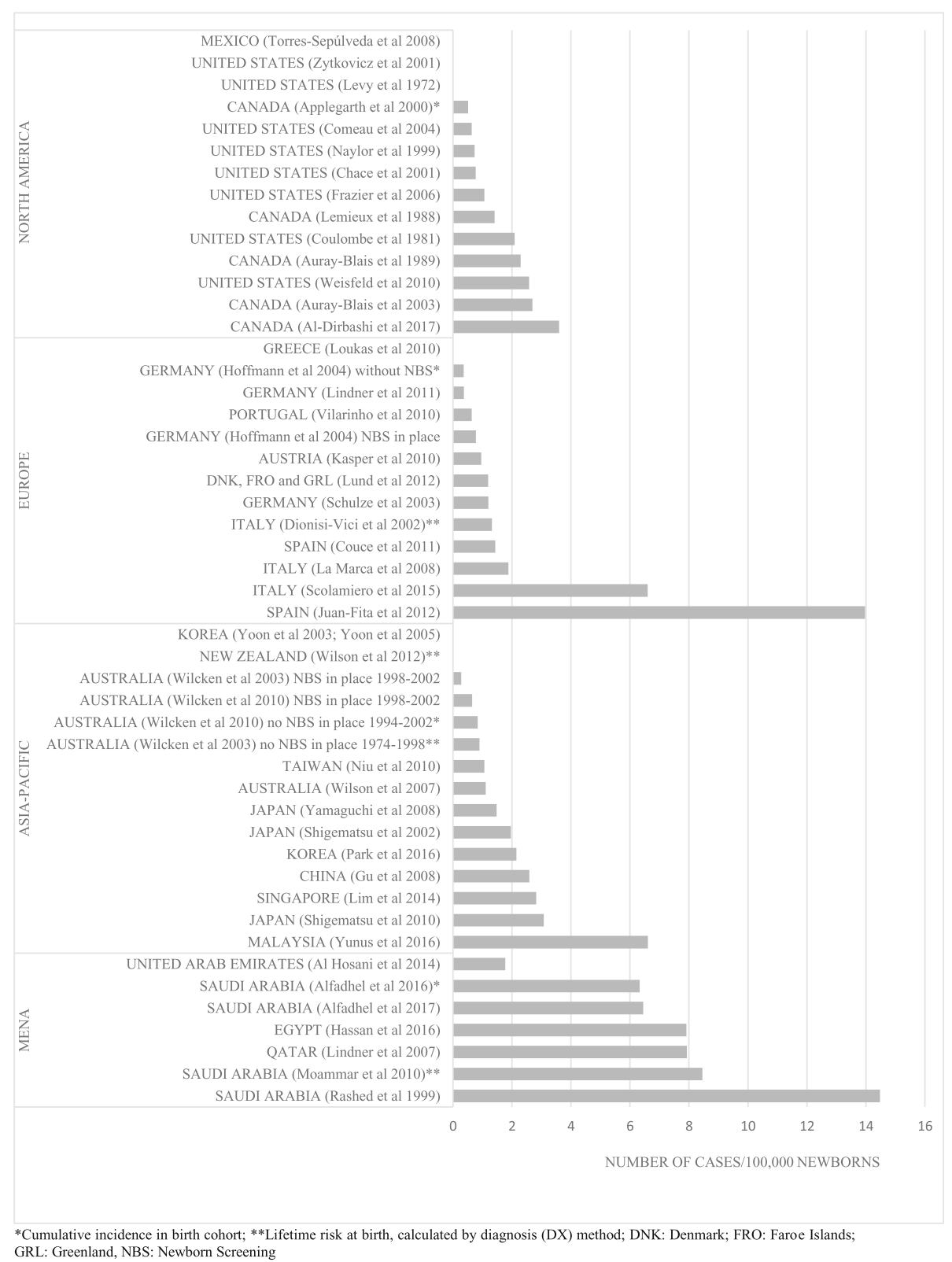

Fig. 2 Estimates on birth prevalence of methylmalonic acidemia. *Cumulative incidence in birth cohort; * Lifetime risk at birth, calculated by diagnosis (DX) method; DNK: Denmark; FRO: Faroe Islands; GRL: Greenland, NBS: Newborn Screening

detection rate of 0.63 per 100,000 newborns. Three other articles reported on screening programs covering $>900,000$ newborns in North America where the detection rates of mut deficiency ranged between 0.32 and 1.19 per 100,000 newborns [39, 42, 43]. Regional and country-specific detection rates are provided in Fig. 3.

In Europe the detection rate varied between $<2.22$ / 100,000 (Greece) and 4.4/100,000 (Italy) [32, 40]. The largest investigated population from the region indicated a detection rate of $0.79 / 100,000$ newborns [23].

In the Asia-Pacific region, the estimate derived from the largest sample size ( $>1,000,000$ newborns) indicated a detection rate of 0.98 per 100,000 newborns in Taiwan [44].

Data from the MENA region indicated a detection rate between 1.21 and 4.52 per 100,000 newborns [11, 25].

Few studies were identified that reported data separately on the epidemiology of MMA due to partial $\left(\mathrm{mut}^{-}\right)$or complete $\left(\right.$ mut $\left.^{0}\right)$ mutase deficiency. Estimations based on reference populations of $>900,000$ newborns provided the following rates for MMA mut ${ }^{-} ;<0.08 / 100,000$ (Taiwan), $<0.11 / 100,000$ (North Carolina), 0.33 (United States) and 0.9 per 100,000 newborns (California) [42-44, 61]. The most reliable estimates of MMA mut ${ }^{0}$ in reference 


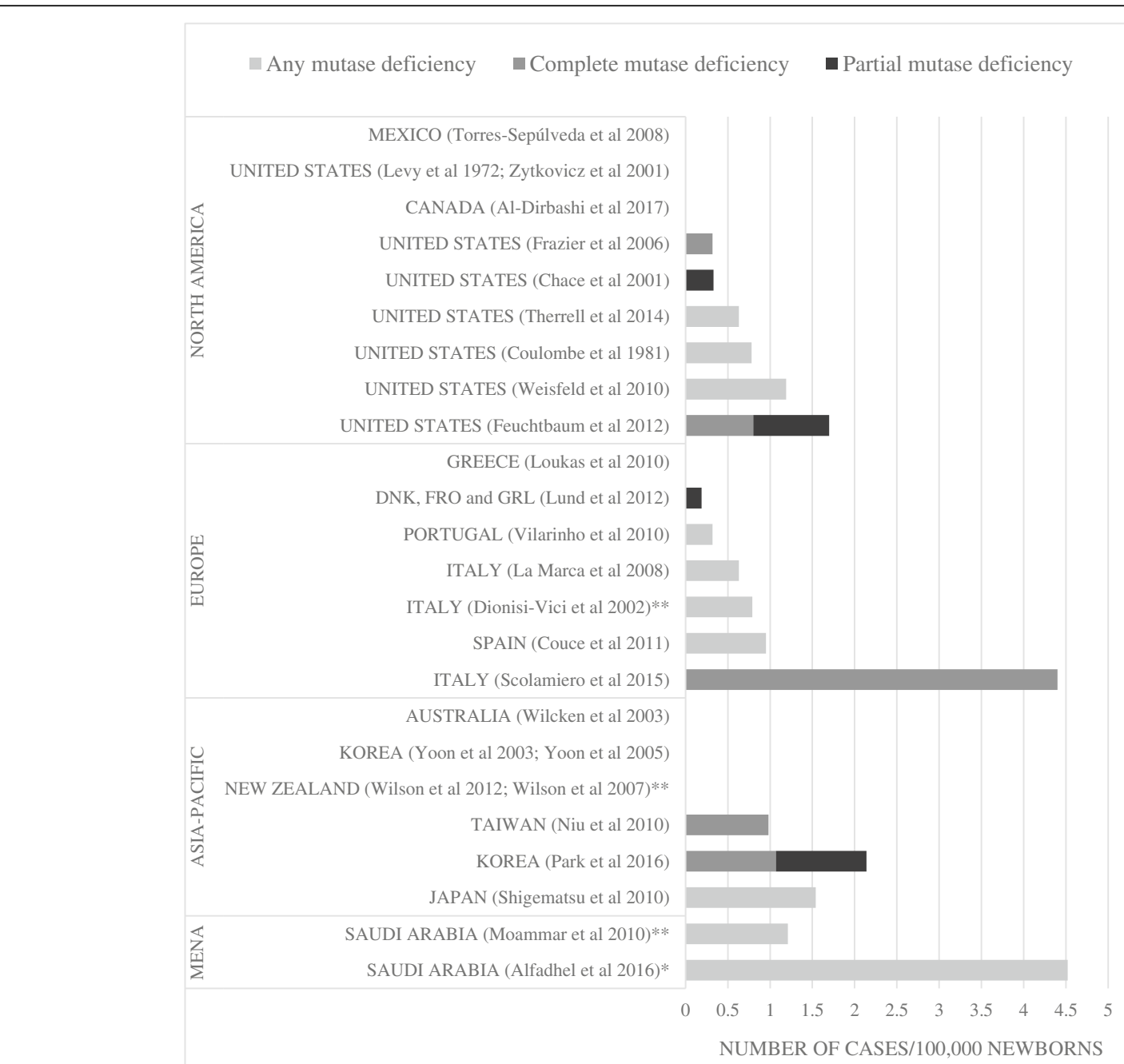

*Cumulative incidence in birth cohort; **Lifetime risk at birth, calculated by diagnosis (DX) method; DNK: Denmark; FRO: Faroe Islands; GRL: Greenland

Fig. 3 Estimates on birth prevalence of methylmalonic acidemias caused by mutase deficiency. ${ }^{*}$ Cumulative incidence in birth cohort; ${ }^{* *}$ Lifetime risk at birth, calculated by diagnosis (DX) method; DNK: Denmark; FRO: Faroe Islands; GRL: Greenland

populations of $>900,000$ newborns are $0.32 / 100,000$ in North Carolina, $0.8 / 100,000$ in California and $0.98 /$ 100,000 in Taiwan [43, 44, 61].

\section{Discussion}

Based on the meta-analyses, the detection rate of MMA and isolated MMA was below 2 cases per 100,000 newborns in North America, Europe and Asia-Pacific regions. In the region of MENA, the meta-analysis results indicated higher disease frequencies for MMA and its isolated form. These results are in line with the recent findings of Chapman et al. (2018) who reported a detection rate of 5.05, 1.44 and 0.18 per 100,000 newborns of isolated MMA in Kuwait, United States and South-West Germany, respectively [62].
The higher disease frequency in the MENA region is most likely due to the higher consanguinity rates in the region. According to Alfadhel et al. [35], the rates of consanguineous marriages are estimated to represent $51-56 \%$ of all marriages in Saudi Arabia and the regional variation of MMA shows a correlation with the tribal distribution across the country [35].

Throughout the years, a minor increase in MMA frequency was noticed in Western countries, possibly due to the introduction of newborn screening programs for inherited metabolic disorder [63] and/or increasing immigration rates in the developed regions [64]. In the region of MENA, in contrast, the decreasing tendency might be attributed to the changing cultural habits and norms and more conscious family planning, which are 
Table 1 Base case and sensitivity analysis by geographic area (SA includes only studies with birth prevalence measure) (detection rate per 100,000 newborns)

\begin{tabular}{|c|c|c|c|c|c|c|c|c|c|c|c|c|}
\hline \multicolumn{7}{|c|}{ Base case } & \multicolumn{6}{|c|}{ Sensitivity analysis (birth prevalence) } \\
\hline \multirow[b]{2}{*}{ Region } & \multicolumn{3}{|c|}{ MMA } & \multicolumn{3}{|c|}{ Isolated MMA } & \multicolumn{3}{|c|}{ MMA } & \multicolumn{3}{|c|}{ Isolated MMA } \\
\hline & $\begin{array}{c}\text { point } \\
\text { estimate } \\
(95 \% \mathrm{Cl})\end{array}$ & $\begin{array}{l}\text { Number } \\
\text { of studies }\end{array}$ & $1^{2}$ & $\begin{array}{c}\text { point } \\
\text { estimate } \\
(95 \% \mathrm{Cl})\end{array}$ & $\begin{array}{l}\text { Number } \\
\text { of studies }\end{array}$ & $1^{2}$ & $\begin{array}{c}\text { point } \\
\text { estimate } \\
(95 \% \mathrm{Cl})\end{array}$ & $\begin{array}{l}\text { Number } \\
\text { of studies }\end{array}$ & $1^{2}$ & $\begin{array}{c}\text { point } \\
\text { estimate } \\
(95 \% \mathrm{Cl})\end{array}$ & $\begin{array}{l}\text { Number } \\
\text { of studies }\end{array}$ & $1^{2}$ \\
\hline North America & $\begin{array}{c}1.22 \\
(0.61-2.01)\end{array}$ & 10 & $79.79 \%$ & $\begin{array}{c}0.38 \\
(0.09-0.79)\end{array}$ & 8 & $53.23 \%$ & $\begin{array}{c}1.36 \\
(0.71-2.20)\end{array}$ & 9 & $76.46 \%$ & $\begin{array}{c}0.42 \\
(0.09-0.91)\end{array}$ & 7 & $53.07 \%$ \\
\hline Europe & $\begin{array}{c}1.12 \\
(0.50-1.91)\end{array}$ & 11 & $79.22 \%$ & $\begin{array}{c}0.60 \\
(0.16-1.23)\end{array}$ & 6 & $2.17 \%$ & $\begin{array}{c}1.55 \\
(0.51-3.02)\end{array}$ & 9 & $79.95 \%$ & $\begin{array}{c}0.60 \\
(0.16-1.23)\end{array}$ & 6 & $2.17 \%$ \\
\hline Asia-Pacific & $\begin{array}{c}0.79 \\
(0.44-1.21)\end{array}$ & $\begin{array}{c}12 \\
\text { (15 cohorts) }\end{array}$ & $45.46 \%$ & $\begin{array}{c}0.51 \\
(0.32-0.74)\end{array}$ & $\begin{array}{c}9 \\
\text { (12 cohorts) }\end{array}$ & $0.00 \%$ & $\begin{array}{c}1.00 \\
(0.46-1.69)\end{array}$ & 11 & $44.76 \%$ & $\begin{array}{c}0.57 \\
(0.27-0.96)\end{array}$ & 8 & $0.00 \%$ \\
\hline MENA & $\begin{array}{c}6.04 \\
(4.02-8.41)\end{array}$ & 6 & $15.78 \%$ & $\begin{array}{c}5.69 \\
(2.54-9.87)\end{array}$ & 2 & NA & $\begin{array}{c}5.60 \\
(2.94-8.94)\end{array}$ & 5 & $21.45 \%$ & NA & NA & NA \\
\hline
\end{tabular}

likely to reduce the frequency of consanguineous marriages $[65,66]$.

As in the vast majority of cases the reported data was not stratified by race/ethnicity, it was not possible to adjust for this factor in the conducted meta-analysis. However, it was addressed by three studies [31, 58, 61]. Lim et al. [58] found that the ethnic distribution of diagnosed cases was comparable to that of the national population in Singapore [58]. Feuchtbaum et al. [61] analyzed the racial/ethnic distribution of MMA subtypes in the United States and found that MMA mut ${ }^{-}$is more frequent among the Middle Easterns, Filipinos, Vietnameses and Southeast Asians, while MMA mut ${ }^{0}$ seemed to be more frequent in Asian East Indian, Chinese and Filipino racial/ethnic groups [61]. Relatively high birth prevalence was reported in Southern Spain by Juan Fita et al. [31] which was explained by the growing immigration rates from North Africa and South America as 6 of the 10 positively screened children originated from parents arriving from the abovementioned regions [31]. These studies may indicate that investigating the ethnicity distribution of diagnosed cases may provide a more accurate picture on disease occurrence.

Due to the rarity of MMA, broadly targeted population-based prevalence studies are not available. However, the reports on the results of newborn screening programs provided valuable, high quality data on the birth prevalence of the disease. One limitation of the analysis is the lack of false positive and false negative data in newborn screening studies; however, where these data were available, the number of positive cases was adjusted. For many newborn screening studies, the follow-up time was not sufficient to appropriately assess the effect. In addition, many reports did not provide the rate of population coverage or the diagnostic tools and algorithms used to define the MMA subtype. To summarize, a newborn screening that includes limited gene sequencing and applies appropriate follow-up can be the "gold standard" for measuring prevalence of most metabolic disorders and possibly non-metabolic genetic disorders as well.

The terminology of the epidemiological measures used in the publications was inconsistent and heterogeneous. One strength of our study is the recategorization and harmonization of all published epidemiological measures.

The $\mathrm{I}^{2}$ statistics indicated substantial heterogeneity across the studies that underlines the necessity of random effects for the meta-analyses. The heterogeneity in the reported detection rates can be only partly explained by the differing type of reference population (screened newborns or all births) and calculation methods (birth prevalence, cumulative incidence in birth cohort, lifetime risk at birth) as the conducted sensitivity analysis (pooling together only birth prevalence data) indicated only minor differences compared to the base-case analysis (Table 1). Other confounders should be also taken into account. For example, the number of undiagnosed cases due to the different public health practices and economic status of the countries could influence the results.

Our findings align well with epidemiological studies published by Peng et al. [67] and Chapman et al. [62] after our review was performed $[62,67]$ and the systematic literature review by the Spanish Health Technology Assessment Agency, which was conducted with the purpose of evaluating the effectiveness of newborn screening programs [68]. However, compared to this work, our review was not restricted to screening programs, therefore, it provides a more comprehensive overview on disease epidemiology. Additionally, isolated MMA caused by mutase deficiency was investigated separately. 


\section{Conclusion}

In several countries, newborn screening programs provide relatively good estimates of the birth prevalence of MMA. However, a considerable evidence gap can be observed in certain geographical regions (e.g. South America, South Africa, Eastern Europe or Russia). The conducted systematic literature review and meta-analysis indicate a geographically uniform disease prevalence with the exception of MENA and confirms that MMA and its subtypes are ultra-rare disorders.

\section{Additional file}

Additional file 1: Table S1. Search strategies and number of hits in different databases. Table S2. Exclusion criteria during the title and abstract screening. Table S3. Definitions of epidemiological measures. (DOCX $20 \mathrm{~kb}$ )

\section{Abbreviations}

CINAHL: The Cumulative Index to Nursing and Allied Health Literature; CRD Database: Centre for Reviews and Dissemination; E-IMD: European registry and network for Intoxication type Metabolic Disorders; MENA: Middle East and North Africa; MMA mut: Methylmalonic acidemia/aciduria caused by the deficiency of methylmalonyl-CoA mutase; MMA mut ${ }^{-}$: MMA due to partial mutase deficiency; MMA mut ${ }^{0}$ : MMA due to complete mutase deficiency; MMA: Methylmalonic acidemia/aciduria; OMIM: Online Mendelian Inheritance in Man

\section{Acknowledgements}

We thank Shu Han and Katherine Kacena who provided their insight and expertise during the review of meta-analysis protocol and results.

\section{Funding}

This study was funded by Moderna, Inc.

\section{Availability of data and materials}

The datasets supporting the conclusions of this article are included in the main text and in its supplementary materials, including the detailed literature search strategy and the PRISMA flow diagram with predefined exclusion criteria for title-abstract and full-text screening of the records. All other datasets used and analysed in the current study are available from the corresponding author upon request.

\section{Authors' contributions}

TZ, TA and KCS initiated the research and drafted the protocols of the systematic literature review and meta-analysis. ZV, LTG and CL reviewed and commented on the draft protocols. TZ, TA and KCS finalized the protocols, conducted the systematic literature review and interpreted the results. ZV conducted the meta-analysis and TZ, TA and LTG interpreted the results. TA and $T Z$ drafted the manuscript. ZV, LTG and $C L$ reviewed and commented on the draft manuscript. TZ, TA and KCS finalized the manuscript. All authors read and approved the current version of the manuscript.

\section{Ethics approval and consent to participate}

The study being a systematic review and meta-analysis is based on secondary analysis of already published data.

\section{Consent for publication}

Not applicable.

\section{Competing interests}

Tímea Almási, Tamás Zelei, Kata Csetneki, and Zoltán Vokó are employees of Syreon Research Institute and performed contracted research for Moderna, Inc. Lin T. Guey and Christine Lukacs are employees of Moderna, Inc. and receive salary and stock options as compensation for their employment. Nonetheless, the content of this paper, as well as the views and opinions expressed therein are those of the Authors and not the organizations that employ them.

\section{Publisher's Note}

Springer Nature remains neutral with regard to jurisdictional claims in published maps and institutional affiliations.

\section{Author details}

${ }^{1}$ Syreon Research Institute, Mexikói str. 65/A, Budapest H-1142, Hungary.

${ }^{2}$ Moderna, Inc., Cambridge, MA, USA. ${ }^{3}$ Department of Health Policy \& Health

Economics, Eötvös Loránd University, Budapest, Hungary.

Received: 3 January 2019 Accepted: 8 April 2019

Published online: 25 April 2019

References

1. Morath M, Okun J, Müller I, et al. Neurodegeneration and chronic renal failure in methylmalonic aciduria — a pathophysiological approach. J Inherit Metab Dis. 2008;31:35-43.

2. Manoli I, Sloan JL, Venditti CP. Isolated Methylmalonic Acidemia. In GeneReviews ${ }^{\circledast}$. Edited by Adam MP, Ardinger HH, Pagon RA, Wallace SE, bean LH, Stephens K, Amemiya a. Seattle WA: University of Washington, Seattle; 1993.

3. Sloan JL, Carrillo N, Adams D, Venditti CP. Disorders of intracellular cobalamin metabolism. In GeneReviews ${ }^{\oplus}$. Seattle: University of Washington; 2018.

4. Fraser JL, Venditti C. Methylmalonic and propionic acidemias: clinical management update. Curr Opin Pediatr. 2016;28:682-93.

5. Kölker S, Cazorla AG, Valayannopoulos V, et al. The phenotypic spectrum of organic acidurias and urea cycle disorders. Part 1: the initial presentation. J Inherit Metab Dis. 2015;38:1041-57.

6. Baumgarter $\mathrm{E}$, Viardot C. Long-term follow-up of 77 patients with isolated methylamalonic acidaemia. J Inherit Metab Dis. 1995;18:138-42.

7. Dionisi-Vici C, Deodato F, Röschinger W, Rhead W, Wilcken B.

'Classical'organic acidurias, propionic aciduria, methylmalonic aciduria and isovaleric aciduria: long-term outcome and effects of expanded newborn screening using tandem mass spectrometry. J Inherit Metab Dis. 2006;29: 383-9.

8. Heringer J, Valayannopoulos V, Lund AM, et al. Impact of age at onset and newborn screening on outcome in organic acidurias. J Inherit Metab Dis. 2016:39:341-53.

9. Hoy D, Brooks $P$, Woolf $A$, et al. Assessing risk of bias in prevalence studies: modification of an existing tool and evidence of interrater agreement. J Clin Epidemiol. 2012;65:934-9.

10. Newcombe RG. Two-sided confidence intervals for the single proportion: comparison of seven methods. Stat Med. 1998;17:857-72.

11. Alfadhel M, Benmeakel M, Hossain MA, et al. Thirteen year retrospective review of the spectrum of inborn errors of metabolism presenting in a tertiary center in Saudi Arabia. Orphanet J Rare Dis. 2016;11:126.

12. Auray-Blais C, Giguère R, Ogier H, Laframboise R, Clow C, Lemieux B. Methylmalonic aciduria: a high incidence of cases detected in the province of Quebec from one million analyses. Current Trends in Infant Screening Amsterdam: Elsevier Science 1989:197-203.

13. Lemieux B, Auray-Blais C, Giguere R, Shapcott D, Scriver C. Newborn urine screening experience with over one million infants in the Quebec network of genetic medicine. J Inherit Metab Dis. 1988;11:45-55.

14. Naylor EW, Chace DH. Automated tandem mass spectrometry for mass newborn screening for disorders in fatty acid, organic acid, and amino acid metabolism. J Child Neurol. 1999;14:S4-8.

15. Schulze A, Lindner M, Kohlmüller D, Olgemöller K, Mayatepek E, Hoffmann GF. Expanded newborn screening for inborn errors of metabolism by electrospray ionization-tandem mass spectrometry: results, outcome, and implications. Pediatrics. 2003;111:1399-406.

16. Shigematsu Y, Hirano S, Hata I, et al. Newborn mass screening and selective screening using electrospray tandem mass spectrometry in Japan. J Chromatogr B. 2002;776:39-48

17. Yoon HR, Lee KR, Kim H, Kang S, Ha Y, Lee DH. Tandem mass spectrometric analysis for disorders in amino, organic and fatty acid metabolism: two year experience in South Korea. Southeast Asian J Trop Med Public Health. 2003; 34(Suppl 3):115-20.

18. Zytkovicz TH, Fitzgerald EF, Marsden D, et al. Tandem mass spectrometric analysis for amino, organic, and fatty acid disorders in newborn dried blood 
spots: a two-year summary from the New England newborn screening program. Clin Chem. 2001:47:1945-55.

19. Al-Thihli K, Al-Murshedi F, Al-Hashmi N, Al-Mamari W, Islam MM, Al-Yahyaee SA. Consanguinity, endogamy and inborn errors of metabolism in Oman: a cross-sectional study. Hum Hered. 2014;77:183-8.

20. Applegarth DA, Toone JR. Incidence of inborn errors of metabolism in British Columbia, 1969-1996. Pediatrics. 2000;105:e10.

21. Wilcken B, Haas M, Joy P, et al. Expanded newborn screening: outcome in screened and unscreened patients at age 6 years. Pediatrics. 2009;124:e241-8.

22. Foss AH, Duffner PK, Carter RL. Lifetime risk estimators in epidemiological studies of Krabbe disease: review and Monte Carlo comparison. Rare Dis. 2013;1:e25212

23. Dionisi-Vici C, Rizzo C, Burlina AB, et al. Inborn errors of metabolism in the Italian pediatric population: a national retrospective survey. J Pediatr. 2002; 140:321-9.

24. Hoffmann GF, von Kries R, Klose D, et al. Frequencies of inherited organic acidurias and disorders of mitochondrial fatty acid transport and oxidation in Germany. Eur J Pediatr. 2004;163:76-80.

25. Moammar H, Cheriyan G, Mathew R, Al-Sannaa N. Incidence and patterns of inborn errors of metabolism in the Eastern Province of Saudi Arabia, 19832008. Ann Saudi Med. 2010:30:271.

26. Wilcken B, Wiley V, Hammond J, Carpenter K. Screening newborns for inborn errors of metabolism by tandem mass spectrometry. N Engl J Med. 2003:348:2304-12.

27. Wilson C, Kerruish NJ, Wilcken B, Wiltshire E, Bendikson K, Webster D. Diagnosis of disorders of intermediary metabolism in New Zealand before and after expanded newborn screening: 2004-2009. NZ Med J. 2012;125:42-50.

28. Wilson C, Kerruish NJ, Wilcken B, Wiltshire E, Webster D. The failure to diagnose inborn errors of metabolism in New Zealand: the case for expanded newborn screening. NZ Med J. 2007;120.

29. Levy HL, Madigan PM, Shih VE. Massachusetts metabolic disorders screening program. I. Technics and results of urine screening. Pediatrics. 1972;49:825-36.

30. Al-Dirbashi OY, McIntosh N, Chakraborty P. Quantification of 2-methylcitric acid in dried blood spots improves newborn screening for propionic and methylmalonic acidemias. J Med Screen. 2017;24:58-61.

31. Juan-Fita M, Egea-Mellado J, Gonzalez-Gallego I, Moya-Quiles M, FernandezSanchez A. Expanded newborn screening in the region of Murcia, Spain. Three-years experience. Medicina clinica. 2012;139:566-71.

32. Scolamiero E, Cozzolino C, Albano L, et al. Targeted metabolomics in the expanded newborn screening for inborn errors of metabolism. Mol BioSyst. 2015;11:1525-35

33. Yunus ZM, Rahman SA, Choy YS, Keng WT, Ngu LH. Pilot study of newborn screening of inborn error of metabolism using tandem mass spectrometry in Malaysia: outcome and challenges. J Pediatr Endocrinol Metab. 2016;29:1031-9.

34. Al Hosani H, Salah M, Osman HM, et al. Expanding the comprehensive national neonatal screening programme in the United Arab Emirates from 1995 to 2011. East Mediterr Health J. 2014:20:17-23.

35. Alfadhel M, Al Othaim A, Al Saif S, et al. Expanded newborn screening program in Saudi Arabia: incidence of screened disorders. J Paediatr Child Health. 2017;53:585-91.

36. Hassan FA, El-Mougy F, Sharaf SA, et al. Inborn errors of metabolism detectable by tandem mass spectrometry in Egypt: the first newborn screening pilot study. J Med Screen. 2016:23:124-9.

37. Lindner M, Abdoh G, Fang-Hoffmann J, et al. Implementation of extended neonatal screening and a metabolic unit in the State of Qatar: developing and optimizing strategies in cooperation with the neonatal screening Center in Heidelberg. J Inherit Metab Dis. 2007;30:522-9.

38. Rashed MS, Rahbeeni Z, Ozand PT. Application of electrospray tandem mass spectrometry to neonatal screening. In Seminars in perinatology Elsevier; 1999: 183-193.

39. Weisfeld-Adams JD, Morrissey MA, Kirmse BM, et al. Newborn screening and early biochemical follow-up in combined methylmalonic aciduria and homocystinuria, cblC type, and utility of methionine as a secondary screening analyte. Mol Genet Metab. 2010;99:116-23.

40. Loukas YL, Soumelas G-S, Dotsikas Y, et al. Expanded newborn screening in Greece: 30 months of experience. J Inherit Metab Dis. 2010;33:341-8.

41. Park K-J, Park S, Lee E, et al. A population-based genomic study of inherited metabolic diseases detected through newborn screening. Ann Lab Med. 2016;36:561-72.

42. Chace DH, DiPerna JC, Kalas TA, Johnson RW, Naylor EW. Rapid diagnosis of methylmalonic and propionic acidemias: quantitative tandem mass spectrometric analysis of propionylcarnitine in filter-paper blood specimens obtained from newborns. Clin Chem. 2001:47:2040-4.

43. Frazier $\mathrm{D}$, Millington $\mathrm{D}, \mathrm{McC}$ andless $\mathrm{S}$, et al. The tandem mass spectrometry newborn screening experience in North Carolina: 1997-2005. J Inherit Metab Dis. 2006;29:76-85.

44. Niu D-M, Chien Y-H, Chiang C-C, et al. Nationwide survey of extended newborn screening by tandem mass spectrometry in Taiwan. J Inherit Metab Dis. 2010;33:295-305.

45. Torres-Sepúlveda M, Martínez-de Villarreal LE, Esmer C, et al. Tamiz metabólico neonatal por espectrometría de masas en tándem: dos años de experiencia en Nuevo León. México Salud Pública México. 2008;50:200-6.

46. Comeau AM, Larson C, Eaton RB. Integration of new genetic diseases into statewide newborn screening: New England experience. In: American Journal of Medical Genetics Part C: Seminars in Medical Genetics: Wiley Online Library; 2004. p. 35-41.

47. Coulombe JT, Shih VE, Levy HL. Massachusetts metabolic disorders screening program. II Methylmalonic Aciduria. Pediatrics. 1981;67:26-31.

48. Auray-Blais C, Giguere R, Lemieux B. Newborn urine screening programme in the province of Quebec: an update of 30 years' experience. J Inherit Metab Dis. 2003;26:393-402.

49. Lindner M, Gramer G, Haege G, et al. Efficacy and outcome of expanded newborn screening for metabolic diseases-report of 10 years from southWest Germany. Orphanet J Rare Dis. 2011;6:44.

50. Vilarinho L, Rocha H, Sousa C, et al. Four years of expanded newborn screening in Portugal with tandem mass spectrometry. J Inherit Metab Dis. 2010;33:133-8

51. Kasper DC, Ratschmann R, Metz TF, et al. The National Austrian Newborn Screening Program-Eight years experience with mass spectrometry. Past, present, and future goalsÖsterreichisches Neugeborenenscreening Programm-Erfahrung über acht Jahre Massenspektrometrie. Vergangenheit, Gegenwart und zukünftige Ziele. Wien Klin Wochenschr. 2010;122:607-13.

52. Lund AM, Hougaard DM, Simonsen $\mathrm{H}$, et al. Biochemical screening of 504,049 newborns in Denmark, the Faroe Islands and Greenland-experience and development of a routine program for expanded newborn screening. Mol Genet Metab. 2012;107:281-93.

53. Couce ML, Castiñeiras DE, Bóveda MD, et al. Evaluation and long-term follow-up of infants with inborn errors of metabolism identified in an expanded screening programme. Mol Genet Metab. 2011:104:470-5.

54. La Marca G, Malvagia S, Casetta B, Pasquini E, Donati MA, Zammarchi E. Progress in expanded newborn screening for metabolic conditions by LCMS/MS in Tuscany: update on methods to reduce false tests. J Inherit Metab Dis. 2008;31:395-404.

55. Yoon H-R, Lee KR, Kang S, et al. Screening of newborns and high-risk group of children for inborn metabolic disorders using tandem mass spectrometry in South Korea: a three-year report. Clin Chim Acta. 2005;354:167-80.

56. Yamaguchi S. Newborn screening in Japan: restructuring for the new era. Ann Acad Med Singap. 2008;37:13-5.

57. Gu X, Wang Z, Ye J, Han L, Qiu W. Newborn screening in China: phenylketonuria, congenital hypothyroidism and expanded screening. Ann Acad Med Singap. 2008;37:107-4

58. Lim J, Tan E, John C, et al. Inborn error of metabolism (IEM) screening in Singapore by electrospray ionization-tandem mass spectrometry (ESI/MS/ MS): an 8year journey from pilot to current program. Mol Genet Metab. 2014;113:53-61.

59. Shigematsu Y, Hata I, Tajima G. Useful second-tier tests in expanded newborn screening of isovaleric acidemia and methylmalonic aciduria. $J$ Inherit Metab Dis. 2010;33:283-8.

60. Therrell BL, Lloyd-Puryear MA, Camp KM, Mann MY. Inborn errors of metabolism identified via newborn screening: ten-year incidence data and costs of nutritional interventions for research agenda planning. Mol Genet Metab. 2014;113:14-26

61. Feuchtbaum L, Carter J, Dowray S, Currier RJ, Lorey F. Birth prevalence of disorders detectable through newborn screening by race/ethnicity. Genet Med. 2012:14:937.

62. Chapman KA, Gramer G, Viall S, Summar ML. Incidence of maple syrup urine disease, propionic acidemia, and methylmalonic aciduria from newborn screening data. Mol Genet Metab Rep. 2018;15:106-9.

63. Pourfarzam M, Zadhoush F. Newborn screening for inherited metabolic disorders; news and views. J Res Med Sci. 2013;18:801.

64. UN-DESA, OECD. World migration in figures. A Joint Contribution by UNDESA and the OECD to the United Nations High-Level Dialogue on 
Migration and Development 2013. Retrieved from: https://www.oecd.org/ els/mig/World-Migration-in-Figures.pdf (26/09/2018).

65. Chaabouni-Bouhamed H. Tunisia: communities and community genetics. Karger: Public Health Genomics; 2008;11:313-23.

66. Hamamy H. Consanguineous marriages: preconception consultation in primary health care settings. J Community Genet. 2012;3:185.

67. Peng G, Shen P, Gandotra N, et al. Combining newborn metabolic and DNA analysis for second-tier testing of methylmalonic acidemia. Genetics Med. 2018;1.

68. Seoane Mato D, Cantero Munoz P, Atienza Merino G. Efectividad clínica del cribado neonatal de errores congénitos del metabolismo mediante espectrometría de masas en tándem. Parte II: acidemia metilmalónica, acidemia propiónica, tirosinemia tipo I. Red Agencia de Evaluación de Tecnologías Sanitarias de Galicia; 2014 Informes de Evaluación de Tecnologías Sanitarias 2015.

Ready to submit your research? Choose BMC and benefit from:

- fast, convenient online submission

- thorough peer review by experienced researchers in your field

- rapid publication on acceptance

- support for research data, including large and complex data types

- gold Open Access which fosters wider collaboration and increased citations

- maximum visibility for your research: over $100 \mathrm{M}$ website views per year

At BMC, research is always in progress.

Learn more biomedcentral.com/submissions 